\title{
Migration and solid solution of stabilizer MgO in PSZ ceramic \\ Liang Zhao ${ }^{1, a}$, Qunhu Xue ${ }^{1,2, b}$ \\ ${ }^{1}$ College of Materials and Mineral Resources, Xi'an University of Architecture and Technology, \\ Xi'an 710055, China; \\ ${ }^{2}$ Shaanxi Techno-institute of Recycling Economy, Xi'an 710055, China. \\ ajrzhaoliang@163.com, bxuequnhu@xauat.edu.cn
}

Keywords: partially stabilized zirconia, zirconia stabilizer, solid solution, migration

\begin{abstract}
The partially stabilized zirconia ceramic samples were fabricated using MgO stabilizer. The solid solution and migration process of stabilizers in zirconia grains under working temperature was studied by XRD, SEM and EDS. Results show that after $1710^{\circ} \mathrm{C} \times 2 \mathrm{~h}$ sintering, $\mathrm{MgO}$ stabilizer in the sample didn't solid-solute completely, part of $\mathrm{MgO}$ enriched in the position of the impurity $\mathrm{SiO}_{2}$ to generating forsterite, stability of zirconia grains didn't reach highest; With increasing heat preservation time under working temperature $1540{ }^{\circ} \mathrm{C}$, solid solution of stabilizer and zirconia stabilization completed in $8 \mathrm{~h}$.
\end{abstract}

\section{Introduction}

The partially stabilized zirconia after stabilizing treatment has good toughness and volume stability, can be widely used in high-performance structural ceramics field and also the main raw material of metering nozzle which is the key functional device of continuous casting ${ }^{[1]}$. Common zirconia stabilizers include $\mathrm{MgO}, \mathrm{Y}_{2} \mathrm{O}_{3}, \mathrm{CaO}, \mathrm{CeO}$, etc ${ }^{[2]}$. Due to the radius of these cations are closer with $\mathrm{Zr}^{4+}$ ionic radius, so they can dissolve in $\mathrm{ZrO}_{2}$ at high temperatures, and generate solid solution with $\mathrm{ZrO}_{2}$ to avoid precipitating during the cooling process. This makes zirconia can maintain high temperature phase below the phase transition temperature ${ }^{[3,4]}$.

In this paper, $\mathrm{MgO}$ was added in monoclinic zirconia powder as stabilizer. In accordance with the firing schedule of zirconia metering nozzle, stabilized zirconia ceramic specimen were fabricated after sintering at $1710^{\circ} \mathrm{C}$ for $2 \mathrm{~h}$. After $1540^{\circ} \mathrm{C}$ (service temperature of metering nozzle) heat preservation for different time, the specimens were cooled by water quenching. Then the distribution of stabilizer and mineral phase of specimens were characterized through XRD, SEM and EDS. Analysis on the process of stabilizer MgO migrating and solid soluting in $\mathrm{ZrO}_{2}$ ceramic can provide important foundation for the research of the zirconia ceramic stabilization.

\section{Experiment}

The chemical composition of raw material was shown in Table 1.

Table 1 Chemical composition of raw material

\begin{tabular}{ccccccccc}
\hline Specimen & $\mathrm{ZrO}_{2}$ & $\mathrm{HfO}_{2}$ & $\mathrm{MgO}$ & $\mathrm{Y}_{2} \mathrm{O}_{3}$ & $\mathrm{CaO}$ & $\mathrm{SiO}_{2}$ & $\mathrm{Al}_{2} \mathrm{O}_{3}$ & $\mathrm{Fe}_{2} \mathrm{O}_{3}$ \\
\hline $\mathrm{A}$ & 94.35 & 2.09 & 2.8 & - & 0.07 & 0.46 & 0.15 & 0.08 \\
$\mathrm{~B}$ & 95.07 & 1.95 & 2.2 & - & 0.08 & 0.53 & 0.13 & 0.04 \\
\hline
\end{tabular}

Specimen $\mathrm{A}$ and $\mathrm{B}$ were fabricated through compression molding, $300 \mathrm{MPa}$ compressed into $\varphi 50 \times 10 \mathrm{~mm}$ cylindrical specimens, sintering at $1710^{\circ} \mathrm{C}$ for $2 \mathrm{~h}$. In order to illustrate the migration and solution process of stabilizer $\mathrm{MgO}$ in the zirconia material, the ceramic specimens after sintering were cooled by water quenching after heat preservation for $0 \sim 12 \mathrm{~h}$ in high temperature furnace at $1540{ }^{\circ} \mathrm{C}$ (service temperature of zirconia metering nozzle). The specimen before sintering is $\mathrm{K}$, the specimens after sintering are A0, A4, A8, A12, B0, B4, B8, B12.

Analyze mineral phase and microstructure of the specimens after heat preservation for $0 \sim 12 \mathrm{~h}$ at $1540{ }^{\circ} \mathrm{C}$ by D/MAX 220 X-ray diffractmeter and Quanta 200 scanning electron microscope. 


\section{Results and discussion}

\section{1 phase composition}

XRD patterns of specimen $A$ and $B$ after heat preservation for $0 \sim 12 \mathrm{~h}$ were shown in Figure 1 .
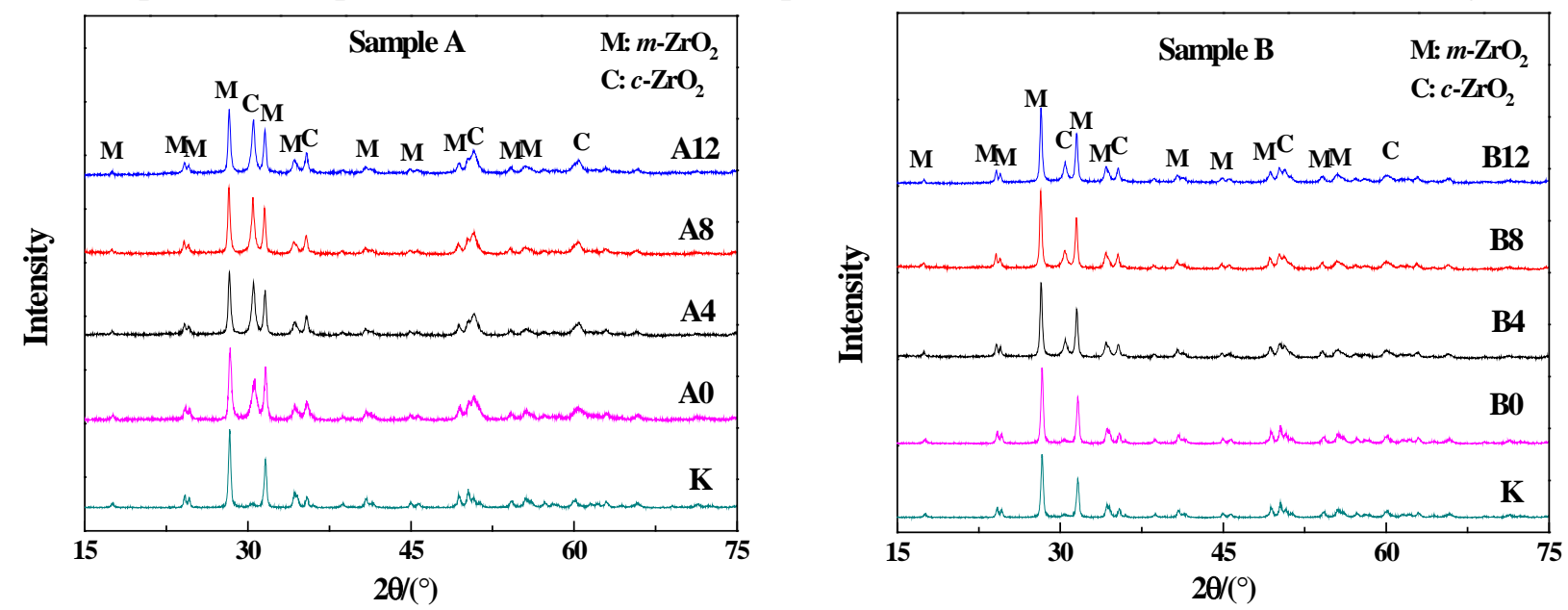

Fig. 1 The XRD spectra of the specimen A and B

From Figure 1, it can be seen that the mineral phase of specimens A and B are mainly composed of monoclinic zirconia before sintering, meanwhile monoclinic and cubic zirconia after sintering. After heat preservation for a certain time at $1540{ }^{\circ} \mathrm{C}$, through comparison of diffraction peak of each specimen in the vicinity of $2 \theta=30^{\circ}$, it can be found that the relative intensity of diffraction peak of cubic phase in specimen A and B gradually increased, that of monoclinic phase gradually decreased with the increase of heat preservation time.

The volume fraction of monoclinic phase can be obtained by the following formula $(1)^{[5,6]}$ :

$$
V_{\mathrm{m}}=\frac{1.6031 I_{\mathrm{m}}(111)}{1.6031 I_{\mathrm{m}}(111)+I_{\mathrm{c}}(111)}
$$

( $I_{\mathrm{m}}$ and $I_{\mathrm{c}}$ are the intensity of monoclinic phase and cubic phase.)

The results were shown in Figure 2.

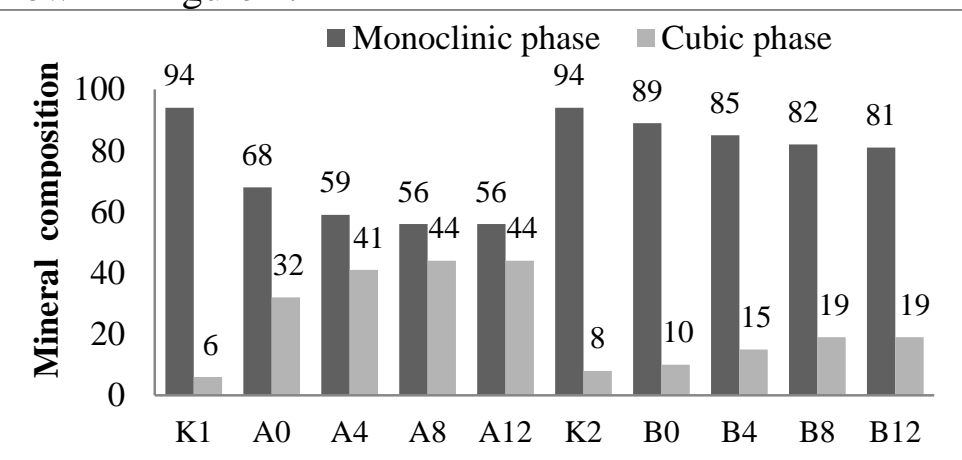

Fig. 2 The XRD analysis results of specimens

The mineral composition results of each specimen are shown in Figure 2. It can be found that the stability degree of zirconia is very sensitive to the content of stabilizer $\mathrm{MgO}$, resulting in the relative content of $\mathrm{m}-\mathrm{ZrO}_{2}$ and $\mathrm{c}-\mathrm{ZrO}_{2}$ in specimens $\mathrm{A}$ and $\mathrm{B}$ markedly different. However the mineral phase of specimens $\mathrm{A}$ and $\mathrm{B}$ don't change after 8 hours heat preservation.

\section{2 microstructure changes}

In order to characterize the migration and solid solution process of stabilizer MgO in zirconia ceramic during the heat preservation process, the results of energy spectrum analysis on specimen A were shown in Figure 3 and Table 2. 

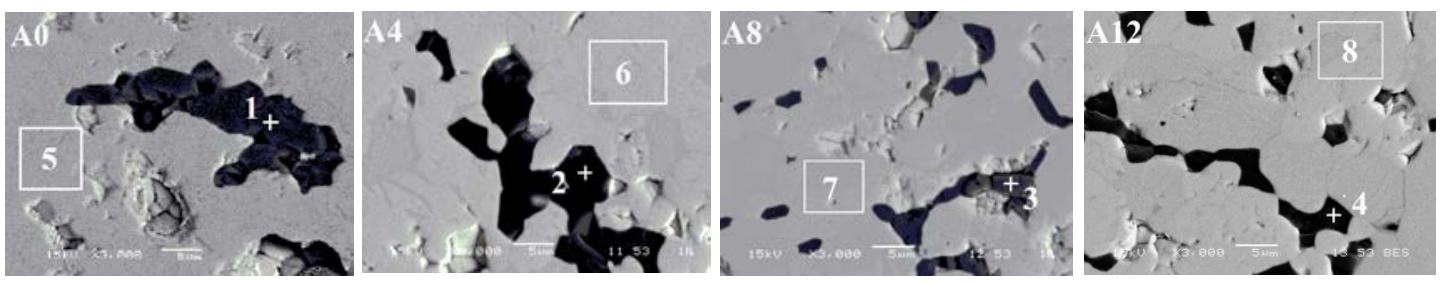

Fig. 3 The EDS results of specimen A after

Table 2 EDS result of specimens (atom \%)

\begin{tabular}{ccccccccc}
\hline Element & 1 & 2 & 3 & 4 & 5 & 6 & 7 & 8 \\
\hline $\mathrm{Zr}$ & 8.8 & 3.7 & 2.6 & 0 & 36.9 & 40.1 & 47.6 & 46.5 \\
$\mathrm{Mg}$ & 27.3 & 34.1 & 32.7 & 35.6 & 2 & 3.1 & 4.1 & 4.2 \\
$\mathrm{Si}$ & 13.8 & 19.1 & 21.2 & 23.2 & 0 & 0 & 0 & 0 \\
$\mathrm{O}$ & 50.2 & 43.1 & 43.6 & 41.2 & 61.1 & 56.7 & 48.3 & 49.3 \\
\hline
\end{tabular}

It can be seen from the position $1 \sim 4$ in the specimen $\mathrm{A}$, after $1710^{\circ} \mathrm{C}$ firing, a part of the $\mathrm{MgO}$ didn't dissolve in zirconia grains, but concentrated in the location where $\mathrm{SiO}_{2}$ (impurity of zirconia raw material) existed. The zirconia raw material in this experiment was monoclinic zirconia which was prepared by zircon $\left(\mathrm{ZrSiO}_{4}\right)$ desilication by plasma method. The preparation method determines a small amount of $\mathrm{SiO}_{2}$ residues in raw material can't be removed completely. The dark mineral phase in location 1 was forsterite $\left(2 \mathrm{MgO} \cdot \mathrm{SiO}_{2}\right)$ concluding from $\mathrm{Mg} / \mathrm{Si}$ atomic ratio. With the increase of heat preservation time, $\mathrm{Mg} / \mathrm{Si}$ ratio decrease from position 1 to 4 . This showed that $2 \mathrm{MgO} \cdot \mathrm{SiO}_{2}$ partially turn into $\mathrm{MgO} \cdot \mathrm{SiO}_{2}$ and $\mathrm{MgO}$. From position 5 to 8 , it can be seen that $\mathrm{MgO}$ content in zirconia increased with the heat preservation time prolonging. It showed that the $\mathrm{MgO}$ decomposed from $2 \mathrm{MgO} \cdot \mathrm{SiO}_{2}$ dissolved into the $\mathrm{ZrO}_{2}$ grains again. The increasing of stabilizer content in grains will lead to $\mathrm{m}-\mathrm{ZrO}_{2}$ transformation to $\mathrm{c}-\mathrm{ZrO}_{2}$. This is consistent with the previous results of XRD.

Due to the specimen A and $\mathrm{B}$ are both stabilized by $\mathrm{MgO}$, so the distribution of the stabilizer could be characterized by specimen A. Figure 5 is the stabilizer distribution map of specimen A after heat preservation at $1540^{\circ} \mathrm{C}$.
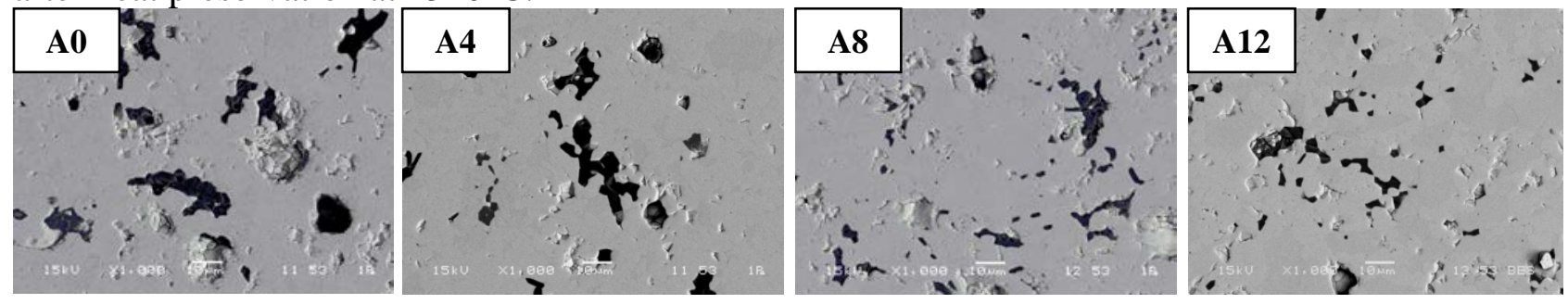

Fig. 4 The distribution of the stabilizer in the specimen $\mathrm{A}$

In Figure 4, with the increase of heat preservation time at $1540^{\circ} \mathrm{C}$, the distribution of dark mineral phase gradually become well punctate from reunite state. This change is obvious in the specimen A and B. This shows that in specimen A and B there was a part of stabilizer MgO enriching in the location of impurity $\mathrm{SiO}_{2}$ to generate forsterite $\left(2 \mathrm{MgO} \cdot \mathrm{SiO}_{2}\right)$, not dissolved into the zirconia grains. After heat preservation at $1540^{\circ} \mathrm{C}$, part of forsterite gradual decompose to $\mathrm{MgO}$ which migrated again and dissolve in zirconia particles to form a certain amount of solid solution.

\section{Summary}

(1) After sintering at $1710{ }^{\circ} \mathrm{C}$ for $2 \mathrm{~h}$, stabilizer migration and solid solution didn't reach a uniform state in $\mathrm{MgO}$ stabilized zirconia ceramic specimens, a part of stabilizer MgO will enrich in the position of $\mathrm{SiO}_{2}$ impurity to generate the forsterite $\left(2 \mathrm{MgO} \cdot \mathrm{SiO}_{2}\right)$, zirconia grains didn't fully and achieve the highest stability.

(2) With the preservation at service temperature $1540^{\circ} \mathrm{C}$, the distribution of the stabilizer enriched position gradually become well punctate from reunite state. The migration and solid 
solution of MgO stabilizer in the specimen and stabilization of the zirconia grains will be completed in $8 \mathrm{~h}$;

(3) Impurity $\mathrm{SiO}_{2}$ in the raw materials of zirconia can lead to the exsolution of stabilizer MgO, which affects the stability of zirconia ceramic.

\section{Acknowledgement}

The present work is supported by the funds of the National Natural Science Foundation of China (51372193) and the Natural Science Basic Research Plan in Shaanxi Province of China (2014JM6224).

\section{References}

[1] J.K.Brimacombe. The challenge of quality in continuous casting processes. Metallurgical and Materials Transactions B. Vol. 30 (1999), p. 1899-1912.

[2] X.M.Yu, B.K.Xu, F.D.Yuan. Stabilizing and Applications of Zirconia. Rare Metals Letters. Vol. 26 (2007) No. 1, p. 28-32.

[3] Z.H.Lin, G.Lin, L.Wu, et al. Phase Structure and Transformation of Zirconia. Chinese Journal of Rare Metals. Vol. 27, (2003) No. 1, p. 49-52.

[4] J.Chevalier, L.Gremillard, A.V.Virkar, et al. The Tetragonal-Monoclinic Transformation in Zirconia: Lessons Learned and Future Trends. Journal of the American Ceramic Society. Vol. 92 (2009) No. 9, p. 1901-1920.

[5] D.L.Porter, A.H.Heuer. Microstructural development in MgO-partially stabilized zirconia (Mg-PSZ). Journal of the American Ceramic Society. Vol. 62 (1979) p. 298-305.

[6] J.X.Zhao, Y.J.Zhang, H.Y.Gong, et al. Fabrication of High-performance $\mathrm{Y}_{2} \mathrm{O}_{3}$ Stabilized Hafnium Dioxide Refractories. Ceramics International, Vol. 41 (2015) p. 5232-5238. 